\title{
Philosophy Education and the Innovation of Contemporary Chinese Philosophy
}

\author{
Yu Xufeng \\ China Jiliang University
}

\begin{abstract}
The cultural function of university education lies in the inheritance and innovation of culture, and philosophy education holds a very important position. The inheritance and innovation of culture constitute an essential part of two major parts of philosophy education: professional education and general education. As a humanistic education, the fundamental purpose of philosophy education is to cultivate people who are free and fully developed. We must not only be able to cultivate philosophical talents, but also be able to cultivate talents with philosophy. Developing philosophy education needs to follow the laws of philosophy education and to improve the quality of philosophy education. Philosophy education is the most important way to cultivate theoretical thinking. On the occasion of the Chinese national rejuvenation going to the forefront of the world, it is a wise move to attach great importance to and develop modern philosophy education, that is, theoretical thinking education.
\end{abstract}

Keywords-Philosophy education; Innovation contemporary Chinese philosophy

\section{INTRODUCTION}

The traits and levels of philosophical education in an era are subject to the traits and levels of philosophical research in this era. Every era has a philosophy that belongs to this era. Its unique characteristics and height reached not only provide an explanation for people's understanding of the philosophical education of this era, but also provide a basis for people to grasp the development direction of philosophy education. However, the innovation motivation of a time philosophy research is not from itself, but from the social life of this era. Therefore, the final interpretation of the traits and development level of philosophy education in an era is not in the philosophical theory itself, but in the society of this era. Philosophy education, innovation in philosophical research, social life and its changes, only by linking these three together and examining them, can we grasp the philosophical education and its development direction in China today.

Modern university education is rich in content, and philosophy education is a part of which has core meaning. College philosophy education includes professional education and general education. The innovation and integration of philosophy education and general education is a fundamental and strategic issue for the teaching and research of contemporary Chinese philosophy and social sciences. Higher education shoulders a dual mission: the inheritance and innovation of culture. The culture of a nation must first be passed on, that is, it can be maintained and continued. Cultural tradition is the continuity, identity or consistency that is presented in generations. Culture must be innovative on the basis of inheritance, in order to continue to develop, full of vitality and vitality. The cultural function of university education lies in the inheritance and innovation of culture. In the entire Chinese education system, the share of philosophy education is not large, but it is in a very important position. As Marx said, philosophy is "the living soul of culture." Contemporary Chinese philosophy education plays a leading role in the education of theoretical thinking in the entire economic, political, social and cultural development. Through reform and innovation to adapt to the development of social needs, the future of Chinese philosophy education will certainly develop significantly.

\section{THE NECESSITY OF PHILOSOPHY EDUCATION IN CONTEMPORARY SOCIETY}

With the increasing complexity of social life and relationships, massive amounts of information are constantly coming to us. In this situation, philosophical thinking that is longer than holistic, general, abstract, reflective, and critical has increasingly highlighted its importance. In the vast ocean of information, it is the "metaphysical" way of thinking that can make the excessive complexity of things necessary to simplify, help us to surface, see directions, goals and ways. As a "view" of the world view, philosophy is not only a superficial phenomenon, but an insight into the inner essence, and thus a grasp of the overall, fundamental and regular nature of the world.

The "view" of philosophy can only be seen far because it stands tall. The concept of nature, history, life, society, culture, education, science, art, religion, values, etc. are all part of the philosophical concept. Although the "view" of various integrations cannot directly solve specific problems, it is the necessary integration in the process of dealing with specific problems. Without this kind of philosophical rationality, people will become trivial transactionalists who do not know the general and do not know the general trend. In the era of "fragmentation" caused by the so-called "information explosion", it is both a worldview and a philosophical reflection of methodology, and a theoretical way of thinking that consciously grasps the self and the world and their relationship rationally.

As the core content of the whole cultural education, philosophy education lies in inheritance and innovation. This essential relationship between inheritance and innovation runs 
through two major parts of philosophy education: professional education and general education. Relatively speaking, philosophy general education focuses on the cultural foundation and quality of philosophy, focusing on the inheritance of philosophical and cultural history; philosophy professional education focuses on the cultivation of the professional foundation and ability of philosophy, focusing on the future innovation of philosophy and culture. Of course, in the general education of philosophy, there is also the relationship between inheritance and innovation, as well as the ability to innovate on the basis of inheritance. Accepting comprehensive philosophical general education and cultivating innovative ability based on cultural heritage is conducive to creative activities in philosophical or non-philosophical fields.

When studying and dealing with the relationship between professional education and general education in philosophy, we need to have a clear sense of consciousness that is consistent with objective reality: in-depth summarization of experience, discovery, problem-solving, analysis, judgment, and effective in understanding and practice. Solve the relationship between professional and general education. Discovering, analyzing, solving problems and promoting the development of philosophy education is innovation. Reform and innovation that conform to objective reality and solve real problems are effective ways to improve the quality of philosophy education and general education. Philosophy education is a humanistic education. The fundamental purpose is to cultivate people who are free and fully developed. The development trend of human beings determines the status quo and future of China's social development.

China has entered a new era of innovation-driven development, and innovation has become the internal driving force for economic and social development. The transformation of China's social development from imitation-driven to innovation-driven has put forward higher requirements for Chinese education, including philosophy education: to cultivate talents with cultural innovation based on cultural heritage. At the same time, society also requires universities to become the base of cultural research and innovation, and to continuously provide new knowledge, new ideas, new theories and new methods in line with the future development needs of China and the world. China will become a strong independent innovation country in the next few decades, and university education, including philosophy education, shoulders a major historical responsibility. With a strong sense of historical responsibility, we should sum up the laws and methods of philosophy professional education and general education, and promote the innovation and integration of philosophy education and general education. University philosophy professional education and general education, like "Bird's wings, two wheels of the car" can not be neglected. Dealing with the two-wing or two-round relationship of philosophy education will enable our philosophy education to develop healthily and rapidly, and play a greater role in the inheritance and innovation of Chinese culture and world culture.

\section{THE ESSENCE OF THE REFORM AND INNOVATION OF PHILOSOPHY EDUCATION}

China has a long way to go to reform, and education reform needs to be deepened. The reforms in the past 40 years have achieved remarkable results. China has become a world education power, but it is not yet an education power. In the historical stage of comprehensively deepening reform, we need to seriously summarize and reflect on the status quo of philosophy education reform and clarify the direction of further reform.

We should be clear about the idea that reform is not an end in itself and cannot be reformed for reform. Reform is the means of development. The prosperity and strength of the country, the progress of society, and the revival of the nation are the goals. No matter which field can be said, reform is focused on improvement, innovation is on excellence, and the value dimension of reform and innovation cannot be missed. The essence of the reform and innovation of philosophy education is to improve excellence and build a high-level philosophy education system with Chinese characteristics. Engels said well: "If a nation wants to stand at the highest peak of science, it can't be without theoretical thinking for a moment." ("Marx and Engels Collection", vol. 9, p. 436) History has proven that philosophy education is the most cultivated theoretical thinking. On the occasion of the Chinese national rejuvenation going to the forefront of the world, it is a wise move to attach great importance to and develop modern philosophy education, that is, theoretical thinking education.

Looking back at history, our philosophy education has experienced a tortuous path. At the beginning of reform and opening up, practice was a big discussion to test the sole standard of truth, and it continued to promote the development of philosophy education. Later, the narrow utilitarian orientation prevailing in the market economy greatly reduced the development space of philosophy education. Until the comprehensive, coordinated and sustainable scientific development concept and new development concept are established, philosophy education returns to its proper position and develops slowly and steadily. The question now is, from the overall situation and trend of China's economic, social and cultural development, what kind of prospects will there be in the coming decades? Will it show a gradual upward trend, or will there be a gradual decline? This is the first basic judgment we need to make when considering and planning the future development strategy of Chinese philosophy education.

This issue should be studied as a major project subject. It needs to have historical, realistic and scientific basis. It cannot be judged solely by personal likes and dislikes. Based on our understanding of the history of various countries and national philosophical education in the world, based on the consideration of Chinese historical and cultural traditions and the development of contemporary economic, social and cultural trends, we tend to be cautiously optimistic. The fate of philosophical education is determined by the extent to which it meets the needs of society. The true needs of the state, society, and people for philosophy are undoubtedly the root of the existence and development of philosophy education. The development of social and human development from 
subsistence to well-being to a higher level is generally a process of upgrading from material needs to spiritual needs. In this sense, philosophy, as a core part of spiritual culture, obviously has a certain "post-development advantage."

China is modernizing, and the developed countries and regions in the world have surpassed industrialization and entered the post-industrial society, the information age. We are also striving to embark on the path of knowledge economy development. In the era of knowledge economy, science, technology, and information have become the primary productive forces, and philosophy seems to be dispensable. In fact, on the contrary, the social role of philosophy is becoming more and more prominent. There are only two reasons for this: First, in the society where the "information tide" continues to hit, only a highly generalized and succinct philosophical way of thinking can make us like "the tide of the children." Second, the "knowledge economy" of the contemporary world is quietly transforming into a "smart economy", and the importance of the "love-wise" way of thinking of philosophy is becoming more and more important. The importance of philosophy by the state, society and the people is likely to become a new trend of thought. . The demand for philosophy and philosophy education in the future world will show a steady upward trend. Our philosophy of professional education and general education (quality) education should improve quality through reform and innovation, and meet the needs of philosophical wisdom for the comprehensive development of society and people.

\section{THE IMPACT OF CHINESE PHILOSOPHY INNOVATION ON PHILOSOPHY EDUCATION}

The innovative power of philosophical research stems from the real social life, and the innovation in philosophical research will have a profound impact on philosophy education. For any society, this transmission relationship is the same. In today's West, especially in the English-speaking world, political philosophy has become an important part of philosophical education, but it was not before the 1970s. For a long time before, political philosophy as a normative theory has been declared dead. If the publication of Rawls's Theory of Justice marks the renaissance of political philosophy in the West, then this revival also means that philosophy once again gains the right to speak on political issues from political science as a concrete science. However, the acquisition of this discourse power is not the result of different types of knowledge redistribution sites, not that Rawls has won from political scientists, but because the problems that arise in Western real social life require philosophical answers. The revival of philosophy by means of normative political discourse shows that complex problems in modern society require not only factual descriptions but also value evaluations, that is, philosophical arguments are needed. In modern society, this normative problem stemming from social needs will provide an inexhaustible motive force for philosophical research, and this innovative progress in philosophical research will also inject new vitality into philosophical education. The situation in China is similar. China's social transformation has stimulated new social needs and shaped new interests, new social structures, and new social relationships. The coexistence of interests and values makes today's Chinese society highly complex, and the normative issues related to the acquisition of meaning and value consensus are increasingly prominent. Today, the study of value theory related to normative issues is further advanced and goes deep into specific issues. From the study of general theory of value to the study of the topic of political philosophy such as fairness, justice, democracy, and freedom is such a kind of advancement.

Since the 1980s, the study of value issues has become a hot topic in the study of Chinese philosophical circles. Value theory has also begun to enter Marxist philosophy textbooks. Because of the special role played by Marxist philosophy in contemporary Chinese philosophy education, value theory has become an important part of the entire Chinese philosophy education. As a normative issue, from the study of value theory to the study of political philosophy, this is the inherent logic of the innovation of Chinese philosophical theory in the last three decades. The study of value theory after the 1980s is not a purely internal discussion of philosophy, but a philosophical study that is developed in response to social needs. It is therefore a secondary political philosophy and value of fairness, justice, equality, freedom, democracy, etc. The study of the problem laid the foundation.

In the past two decades, issues of fairness, justice, equality, democracy, and freedom have been the focus of more and more philosophers, both as a political philosophy theme and as a value theme. These political philosophical or value philosophical issues have broken the boundaries between the "Chinese and Western horses" and gradually formed a philosophical research field with common problems as the link. This kind of problem-based fusion of disciplines provides an example of the seemingly extravagant "opening up the West and West Malaysia". Its significance is not limited to the role of demonstration, but changes the situation of philosophical research in related fields from content, structure and direction. The impact of this innovative development in philosophical research on Chinese philosophy education is enormous. This influence is not limited to the philosophical professional education in universities. More importantly, it will play a role in shaping new civic values and constructing new social consensus. It is a contemporary China with diverse interests, values and ideas. The long-term stable development of society provides spiritual support.

Social life under new social conditions requires new values to provide effective integration for this society. Therefore, the core values of socialism are undoubtedly an important part of Chinese philosophy education in a historical period that is quite long today and in the future. This philosophical education not only requires philosophical innovation in the fields of ethics, value theory, political philosophy, etc., but also requires the philosophical research in these fields to be based on the social transformation of today's China rather than just relying on previous theories to carry out theoretical innovation. This requires us to always pay attention to China's own problems when conducting research and philosophical education on these philosophical issues. Today, China's socialist market economic system has been initially established, but the basic social structure is still being formed. Will the basic structure of this society be more equal or polarized? In this basic structure of 
society, how is the basic system of individual liberty and public interest arranged? How is the relationship between democracy and concentration? We don't have any ready-made theories to draw directly from. To answer these questions, we need to start from the reality of China and construct Chinese philosophical theories that belong to this era.

\section{CONCLUSION}

In short, today's social development in China requires the support of innovative philosophical theories, which must be a comprehensive innovation in which various ideological resources support each other. This innovation must follow the basic principles and methods of Marxism, and it should be revised, supplemented and developed on the basis of real life. It is necessary to absorb the ideological resources of foreign philosophical theory and traditional Chinese philosophical theory, but also to China itself. Only the philosophical theory formed on this basis can provide theoretical support for the current and future Chinese philosophy education.

\section{REFERENCES}

[1] Li Zhen, Li Yan. Practice and Thinking of the Specialized Teaching of Marxist Philosophy in Colleges and Universities in the New Century[J]. Journal of Changchun Institute of Technology: Social Science Edition, 2003(1): 53-55.

[2] Li Yan. What We Should Give Students in the New Century--Practice and Reflection on the Teaching Reform of Marxist Philosophy[J]. Journal of Changchun University of Technology: Higher Education Research Edition, 2002(2): 48-50.

[3] Xia Wei. The Status Quo and Thinking of Medical Students Studying Marxist Philosophy[J].Zhejiang Medical Education,2002,0(0):11-14.

[4] Xiao Shengfu [1]. Analysis of the Teaching Status Quo of Marxist Philosophy Principle Course and Its Causes and Countermeasures[J]. Journal of Guangzhou Maritime College,2004,12(1):60-62.

[5] Li Li. Discussion on the Teaching Method of "Marxist Philosophical Principles"[J]. Journal of Anhui University of Science and Technology: Social Science Edition, 2002, 4(1): 79-80. 